\title{
II SIMPÓSIO DE ALIMENTOS E III SEMANA ACADÊMICA DE CIÊNCIA E TECNOLOGIA DE ALIMENTOS - 2017
}

\section{SIMPÓSIO DE ALIMENTOS AND III SEMANA ACADÊMICA DE CIÊNCIA E TECNOLOGIA DE ALIMENTOS - 2017}

\author{
P. S. MONTEIRO ${ }^{1}$, A. M. O. SIQUEIRA ${ }^{2}$ \\ ${ }^{1}$ Universidade Federal de Viçosa, Instituto de Ciências Agrárias, Rio Paranaíba, MG, Brasil \\ ${ }^{2}$ Universidade Federal de Viçosa, Departamento de Química, Viçosa/MG, Brasil \\ E-mail: psmonteiro@ufv.br
}

a r i c le info

Article history:

Received 12 May 2017

Accepted 3 August 2017

Available online 20 September 2017
PALAVRAS-CHAVE: Divulgação Científica, Educação, Comunicação. KEYWORDS: Scientific Disclosure, Popular Science, Education, Communication

\section{INTRODUÇÃ̃O}

Promovidos, em sua maioria, por instituições de ensino superior, institutos de pesquisa, órgãos governamentais ou sociedades científicas e associações de classe, os eventos científicos são imprescindíveis para atualização profissional de professores, pesquisadores e estudantes de graduação e de pósgraduação, bem como a intercâmbio de contatos pessoais e avaliação de trabalhos inéditos, finalizados ou em andamento (TARGINO, 2000).

Para GUIMARÃES e HAYASHI (2015) “os eventos científicos (congressos, simpósios) constituem os espaços privilegiados para apresentação de trabalhos em andamento, pois permitem a apresentação prévia aos pares, possibilitando a incorporação das apreciações e novos insights". Apesar disso, conforme bem destacao por GUIMARÃES e HAYASHI (2015) "os eventos científicos constituem-se em importantes canais de comunicação da ciência, embora as publicações de trabalhos completos e resumos apresentados nos eventos não tenham o mesmo status de outros tipos de publicação oriundos dos canais formais, especialmente o artigo científico."

Na sociedade contemporânea, a informação, o conhecimento e a comunicação têm se destacado fortemente e "são estratégias que favorecem a compreensão da complexidade do mundo, bem como os interesses e as influências de determinados grupos sociais dentro de um contexto político e social" (ESPERANÇA, FILOMENO e LAGE,2014). Neste cenário, a educação científica, conforme Esperança, Filomeno e Lage (2014) "possibilita aos cidadãos 


\section{The Journal of Engineering and Exact Sciences - \\ JCEC}

ISSN: 2527-1075

um reconhecimento da ciência como parte integrante da cultura humana, uma vez que o seu processo de produção é muito influenciado pelo momento histórico da sociedade."

Assim, "a divulgação científica como preceito fundamental busca a socialização de informações científicas e tecnológicas, visando incluir a população na produção e compartilhamentos de saberes e conhecimentos' (ESPERANÇA, FILOMENO e LAGE,2014).

Dentro desta ótica, como bem destacam Paz et al. (2014) "os eventos científicos vêm se consolidando como um importante espaço de dinamização de discussões e avanços de pesquisas de uma determinada especialidade, promovendo a integração do ensino", pesquisa e extensão, bem como o desenvolvimento cultural e científico, através da divulgação científica informal.

A importância da divulgação científica é enfatizada por CAMPELLO (2000):

"A pesquisa científica é um processo complexo, e durante sua execução o pesquisador assume diversas funções: a de líder de equipe, a de captador de recursos, a de comunicador, dentre outras. A função de comunicador é de fundamental importância nesse processo, pois o pesquisador precisa estar constantemente atualizado em relação aos avanços de sua área, inteirando-se do que outros cientistas estão fazendo e, por outro lado, mostrando o que ele próprio está realizando, como forma de ter seu trabalho avaliado pelos seus pares e de garantir a prioridade de suas descobertas."

Paz et al. (2014) ressaltam que apesar das "dificuldades de realização e apoio às iniciativas científicas, sobretudo às atividades de caráter local e regional, esses eventos vêm adquirindo importância e frequência crescentes na comunidade científica - sobretudo por meio da divulgação de resultados e impactos alcançados - e, cada vez mais, são reportados sob a forma de registros e publicações..., servindo de incentivo para a participação de maior público e para o surgimento de outras iniciativas acadêmicas. "

Considerando as premissas levantadas, o Simpósio de Alimentos (SIMAL) e a Semana Acadêmica de Ciência e Tecnologia de Alimentos (SEACAL) são eventos científicos organizados pelos professores e estudantes do curso de Ciência e Tecnologia de Alimentos da Universidade Federal de Viçosa, Campus Rio Paranaíba.

O SIMAL e a SEACAL têm como objetivos apresentar, aos estudantes do curso de Ciência e Tecnologia de Alimentos e à comunidade universitária em geral, os desafios e tendências relacionados à profissão e agregar valor à formação dos estudantes, ampliando a sua visão em relação à sua área de atuação.

Os eventos também objetivam fomentar maiores discussões sobre os vários temas da área de Ciência e Tecnologia de Alimentos e, desta forma, contribuir para o desenvolvimento da região do Alto Paranaíba, que tem a sua economia baseada na agricultura e pecuária, sendo 


\section{The Journal of Engineering and Exact Sciences -}

JCEC

ISSN: 2527-1075

reconhecida como uma das regiões mais importantes para o agronegócio do país. No entanto, também apresenta elevado potencial para o desenvolvimento do setor industrial de alimentos. Sendo assim, eventos desta natureza, além de consolidar a proposta do curso de Ciência e Tecnologia de Alimentos, também poderão incentivar parcerias público-privadas para a realização de projetos agroindustriais na região.

Nesta edição, realizada entre os dias 9 e 12 de maio de 2017, ambos eventos, SIMAL e SEACAL foram realizados simultaneamente e possibilitaram aos inscritos, a participação em palestras, minicursos práticos e teóricos, a apresentação de trabalhos científicos, na forma de resumos expandidos, e visitas técnicas a empresas do setor industrial de alimentos, conforme pode ser observado nas Figura 1 e 2 .

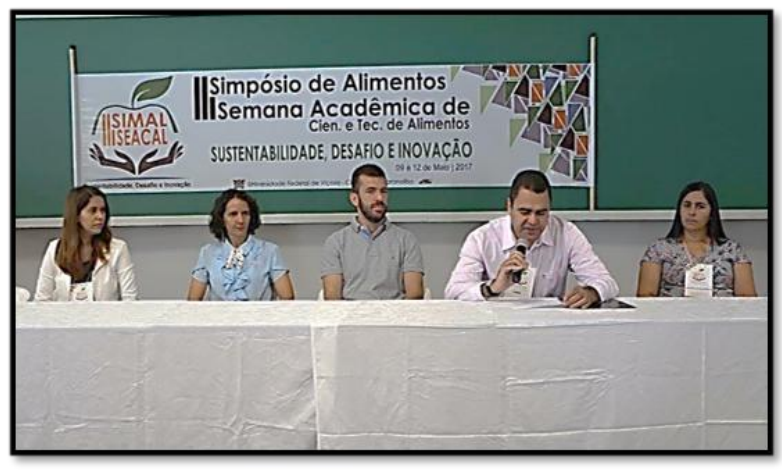

Solenidade de abertura

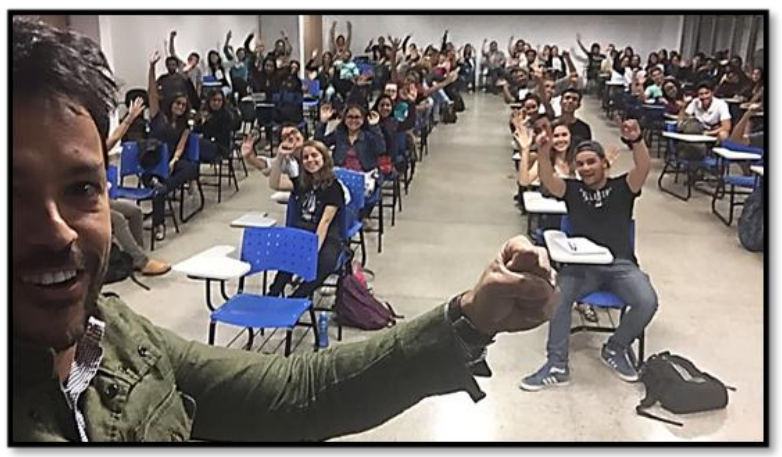

Palestra

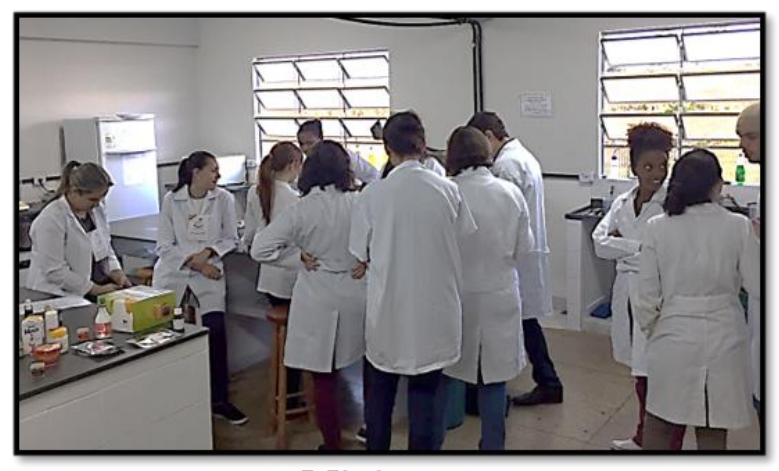

Minicurso

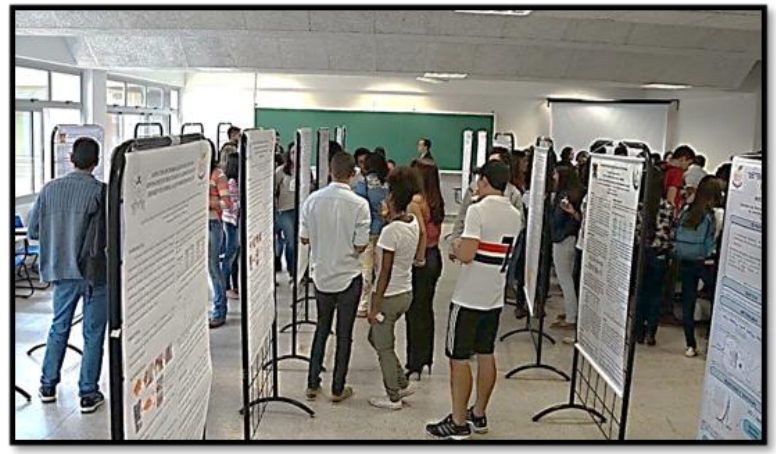

Apresentação de trabalhos

Figura 1 - Atividades realizadas durante o II Simpósio de Alimentos e III Semana Acadêmica de Ciência e Tecnologia de Alimentos. 


\section{The Journal of Engineering and Exact Sciences - \\ JCEC}

ISSN: 2527-1075

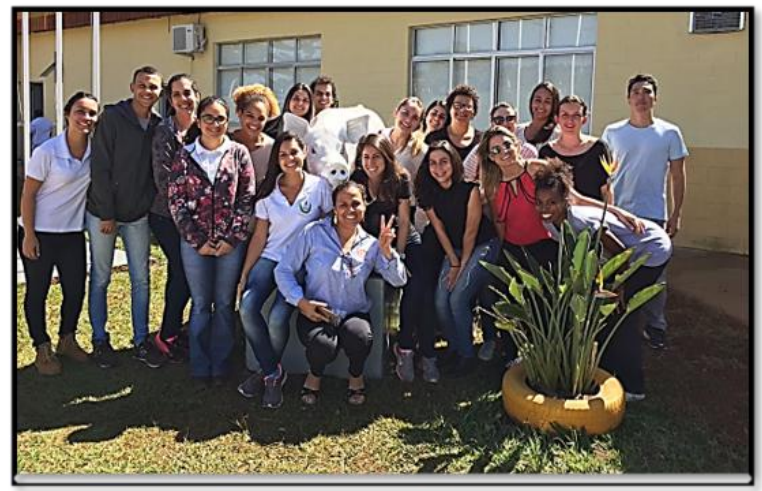

Visita técnica

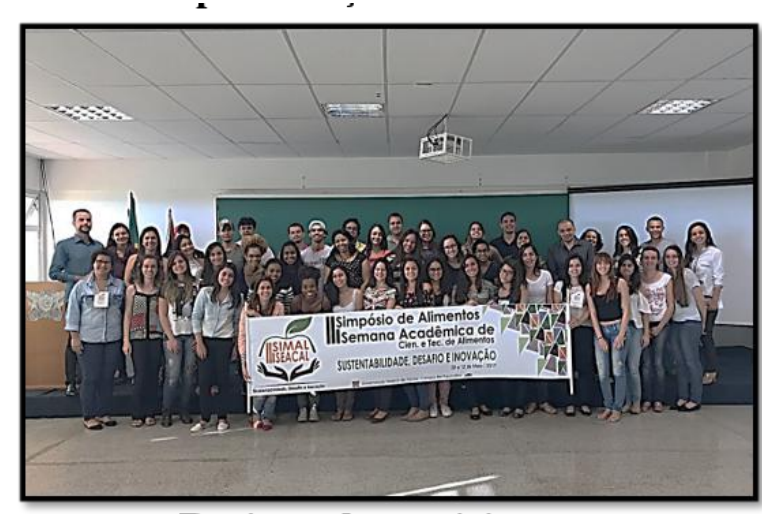

Registro de participantes

Figura 2 - Outras atividades realizadas durante o II Simpósio de Alimentos e III Semana Acadêmica de Ciência e Tecnologia de Alimentos.

A Comissão Coordenadora dos eventos trabalhou durante 9 meses na organização das atividades propostas e contou com o apoio do Instituto de Ciências Agrárias (IAP); da Advice Food, Empresa Júnior de Ciência e Tecnologia de Alimentos; do Centro Acadêmico do curso e do SEBRAE MG.

De acordo com Moita e Andrade (2009), ensino, pesquisa e extensão constituem a base fundamental das Universidades brasileiras, a qual não pode ser compartimentada. Neste contexto, as atividades realizadas durante os eventos seguiram o princípio da indissociabilidade entre ensino, pesquisa e extensão, e contribuíram para o maior desenvolvimento das habilidades dos envolvidos em relação ao planejamento e gestão de projetos.

Os eventos foram realizados nas dependências da UFV, campus Rio Paranaíba e tiveram 90 inscritos nesta edição. Foram recebidos 23 resumos expandidos, entre os quais foram selecionados os 5 melhores trabalhos para apresentação oral. Nesta edição, além dos estudantes, técnicos e professores da UFV, participaram dos eventos, estudantes e professores de outras instituições de ensino superior, como o Instituto Federal de Minas Gerais - Campus Bambuí, Universidade Federal de Lavras e Universidade Federal de Uberlândia.

Foram recebidos palestrantes de várias instituições, como o Centro Universitário São Lucas, Escola Superior de Agricultura "Luiz de Queiroz" (Esalq/USP), Faculdades Integradas Aparício Carvalho, Instituto Federal do Sudeste de Minas Gerais, SEBRAE, Universidade Federal de Lavras, Universidade Federal de São João Del Rei, Universidade Federal do Triângulo Mineiro e Universidade Federal de Viçosa, que engrandeceram os eventos com suas valiosas contribuições 


\section{CONSIDERAÇÕES FINAIS}

O II SIMAL e a III SEACAL alcançaram os objetivos propostos, tendo proporcionado um amplo debate sobre os vários temas da área de Ciência e Tecnologia de Alimentos. Além disso, os eventos contribuíram para aumentar o interesse dos estudantes pelo curso, pelas linhas de pesquisa e pelo mercado de trabalho que envolve o profissional da área.

O período dedicado às atividades desenvolvidas, também proporcionou uma valiosa interação entre os estudantes de diferentes períodos do curso e de diferentes instituições, contribuindo para divulgar e fortalecer as atividades relacionadas ao profissional da área de Ciência e Tecnologia de Alimentos.

\section{AGRADECIMENTOS}

Os autores agradecem aos professores, estudantes e técnicos administrativos que contribuíram para o sucesso dos eventos, bem como aos ministrantes de minicursos ou palestras.

\section{REFERÊNCIAS}

CAMPELlO, B. S. Encontros científicos. In: CAMPELlO, B. S.; CENDÓN, B. V.; KREMER, J. M. (Org). Fontes de informação para pesquisadores e profissionais. Belo Horizonte: Editora da UFMG, 2000.

ESPERANÇA, T. C. R. B.; FILOMENO, C. E. S.; LAGE, D. de A. Divulgação científica no ambiente escolar: uma proposta a partir do uso de mídias digitais. Disponível em: $<$ http://www.sbenbio.org.br/wordpress/wp-content/uploads/2014/11/R0859-1.pdf>. Acesso em 03 abril 2017.

GUIMARÃES, V. A. L.; HAYASHI, M. C. P. Os Eventos Científicos: espaços privilegiados para a comunicação da ciência. Comunicologia-Revista de Comunicação e Epistemologia da Universidade Católica de Brasília, v. 7, n. 2, p. 204-229, 2015.

MOITA, F. M. G. S. C., ANDRADE, F. C. B. Ensino-pesquisa-extensão: um exercício de indissociabilidade na pós-graduação. Revista Brasileira de Educação, v. 14, n. 41, p. 269-280, maio/ago. 2009. 
PAZ, J. R. L. da ; SANTOS, M.V.P.; SILVA, W. P.; MOREIRA, A. L. C. SANTANA, C. C. A importância da organização de eventos acadêmicos na formação do biólogo: a iniciativa do BioVertentes. Em Extensão (UFU. Impresso), v. 13, p. 51-60, 2014.

TARGINO, M. das G. Comunicação científica: uma revisão de seus elementos básicos. Informação \& Sociedade: Estudos, João Pessoa, v. 10, n. 2, p. 67-85, 2000. 